\title{
Interfacial Reactions between Liquid Indium and Silver Substrates
}

\author{
Y.M. LIU, Y.L. CHEN, and T.H. CHUANG \\ Institute of Materials Science and Engineering, National Taiwan University, Taipei, Taiwan, ROC \\ The morphology and growth kinetics of intermetallic compounds formed at the \\ interface between liquid indium and silver substrates in the temperature range \\ from $473 \mathrm{~K}$ to $673 \mathrm{~K}$ were studied. Electron microprobe (EPMA) analysis and $\mathrm{x}$ - \\ ray diffraction (XRD) revealed that the intermetallic compound $\mathrm{Ag}_{2}$ In formed as \\ scallops. The growth followed parabolic kinetics, suggesting that the growth was \\ diffusion-controlled. Moreover, the activation energy calculated from the \\ Arrhenius plot of growth reaction constants was $41.55 \mathrm{KJ} / \mathrm{mole}$. Also, the \\ relationship between the wettability of liquid indium on the surface of silver \\ substrates and their interfacial reactions was clarified.
}

Key words: Indium, silver, intermetallic compound, kinetics, wettability

\section{INTRODUCTION}

Soldering is widely used for electronic packaging processes such as surface mount technology (SMT), pin-through-hole (PTH), ball grid array (BGA), and flip-chip (FC) interconnects. Alloys of lead-tin system are the most common solder alloys used. However, because lead can result in environmental pollution, the development of lead-free solders has become an important task for electronic industries. Even though the indium-base solders are less commonly used than traditional lead-tin or tin-based solders, they possess excellent fatigue resistance. ${ }^{1-3}$ Silver is a typical thick film material for hybrid circuits. The solderability of indium on silver substrates depends on the reactions occurring at the In/Ag interface, and the compositions and growth kinetics of interfacial reaction products (most of which are intermetallic compounds). Also the wettability of liquid indium on the surface of silver substrates will likely be influenced by the formation of these intermetallic compounds.

The interfacial reactions of traditional lead-tin or tin-based solders with silver substrates have been studied in the past. The formation of the intermetallic compound $\mathrm{Ag}_{3} \mathrm{Sn}$ at the interface of molten $60 \mathrm{Sn} 40 \mathrm{~Pb}$ and silver substrate was observed. ${ }^{4,5}$ The kinetics and mechanisms for the growth of intermetallic compounds have also been studied. ${ }^{6}$ In contrast to reports in the literature on the interfacial reactions between

(Received November 12, 1999; accepted April 18, 2000) tin and silver, studies on $\mathrm{In} / \mathrm{Ag}$ interfaces are rare. L. Bernstein found that an intermetallic compound $\mathrm{Ag}_{2} \mathrm{In}$ formed in the temperature range from $523 \mathrm{~K}$ to $673 \mathrm{~K}^{7,8}$ while D.M. Jacobson et al. reported that indium reacted with silver to form the intermetallic compound $\mathrm{AgIn}_{2}$ between temperatures above the melting point of indium and below $439 \mathrm{~K} .{ }^{9}$ This study is concerned with the morphology and growth kinetics of intermetallic compounds formed at the interface between liquid indium and silver substrates in the temperature range from $473 \mathrm{~K}$ to $673 \mathrm{~K}$. The relationship between the wettability of liquid indium on the surface of silver substrates and their interfacial reactions is also examined.

\section{EXPERIMENTAL}

Silver substrates with a dimension of $12 \mathrm{~mm} \times$ $12 \mathrm{~mm} \times 1 \mathrm{~mm}$ were cut from a silver plate of 99.95 wt.\% purity. A 99.99 wt.\% purity indium ingot was rolled into $1 \mathrm{~mm}$ thickness and cut to the same size in the same manner as the silver substrates. The contact surfaces of $\mathrm{Ag}$ substrates were polished with fine alumina powder. For the purpose of investigating interfacial reactions, an indium specimen was inserted between two silver substrates as a sandwich. The assemblies were then heated at $473,498,523$, $548,573,623$, and $673 \mathrm{~K}$ in an infrared furnace under a vacuum of $10^{-3}$ torr for various lengths of time. After heating, the samples were purged with nitrogen to cool in approximately $3 \mathrm{~min}$. The solder specimens were then mounted in resin, cross sectioned and 

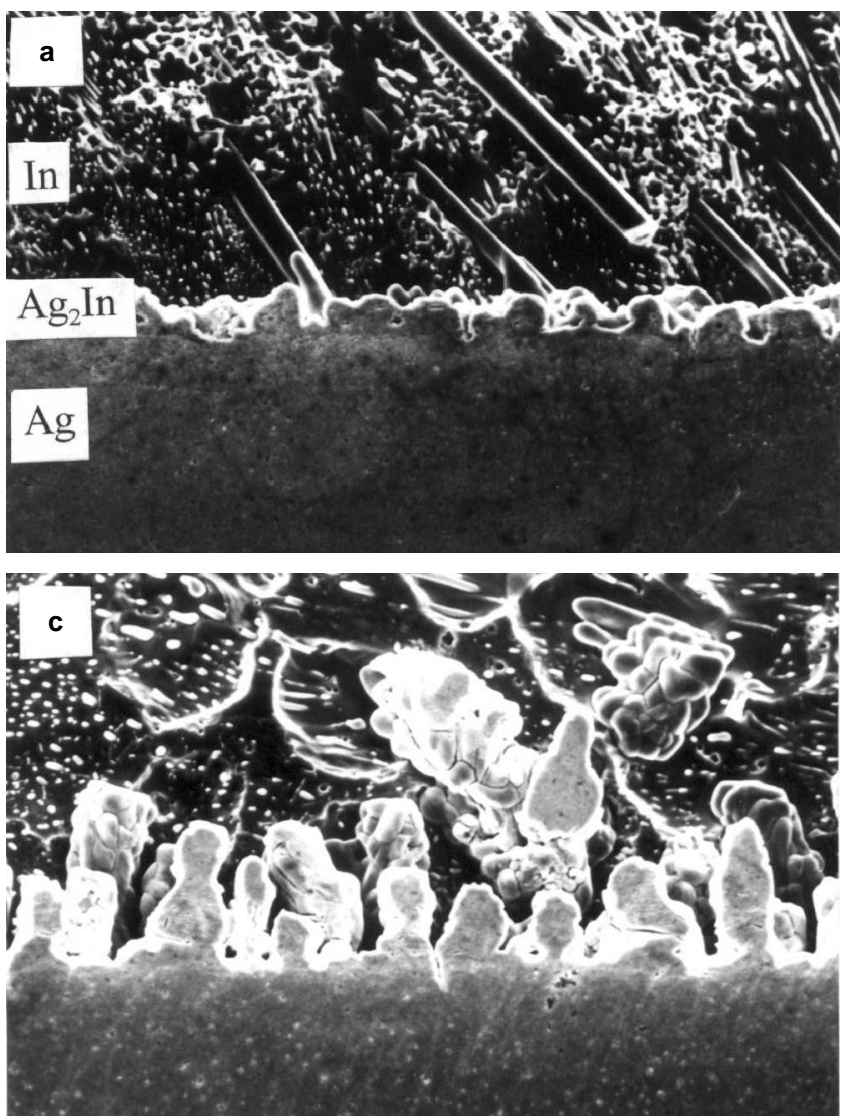
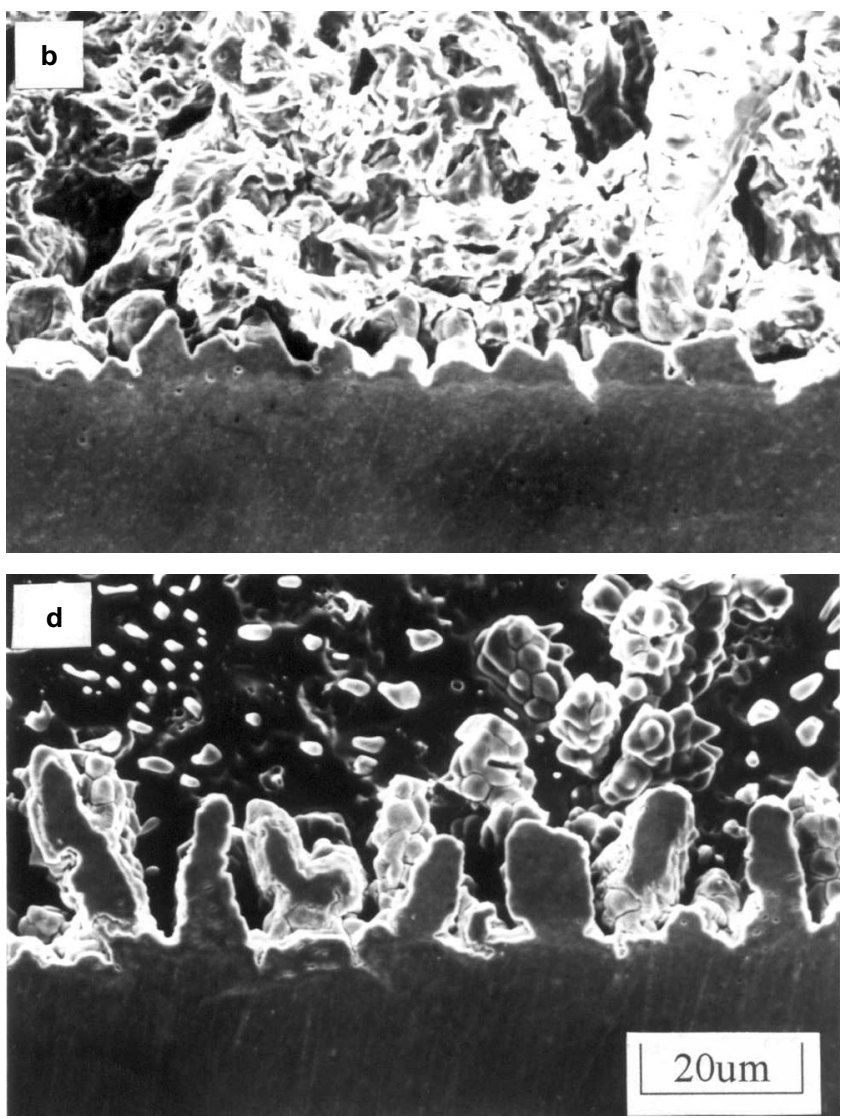

Fig. 1. Morphology of Ag/ln interfacial reaction product (a) $573 \mathrm{~K}, 5 \mathrm{~min}$; (b) $573 \mathrm{~K}, 10 \mathrm{~min}$; (c) $573 \mathrm{~K}, 20 \mathrm{~min}$; and (d) $573 \mathrm{~K}, 30 \mathrm{~min}$.
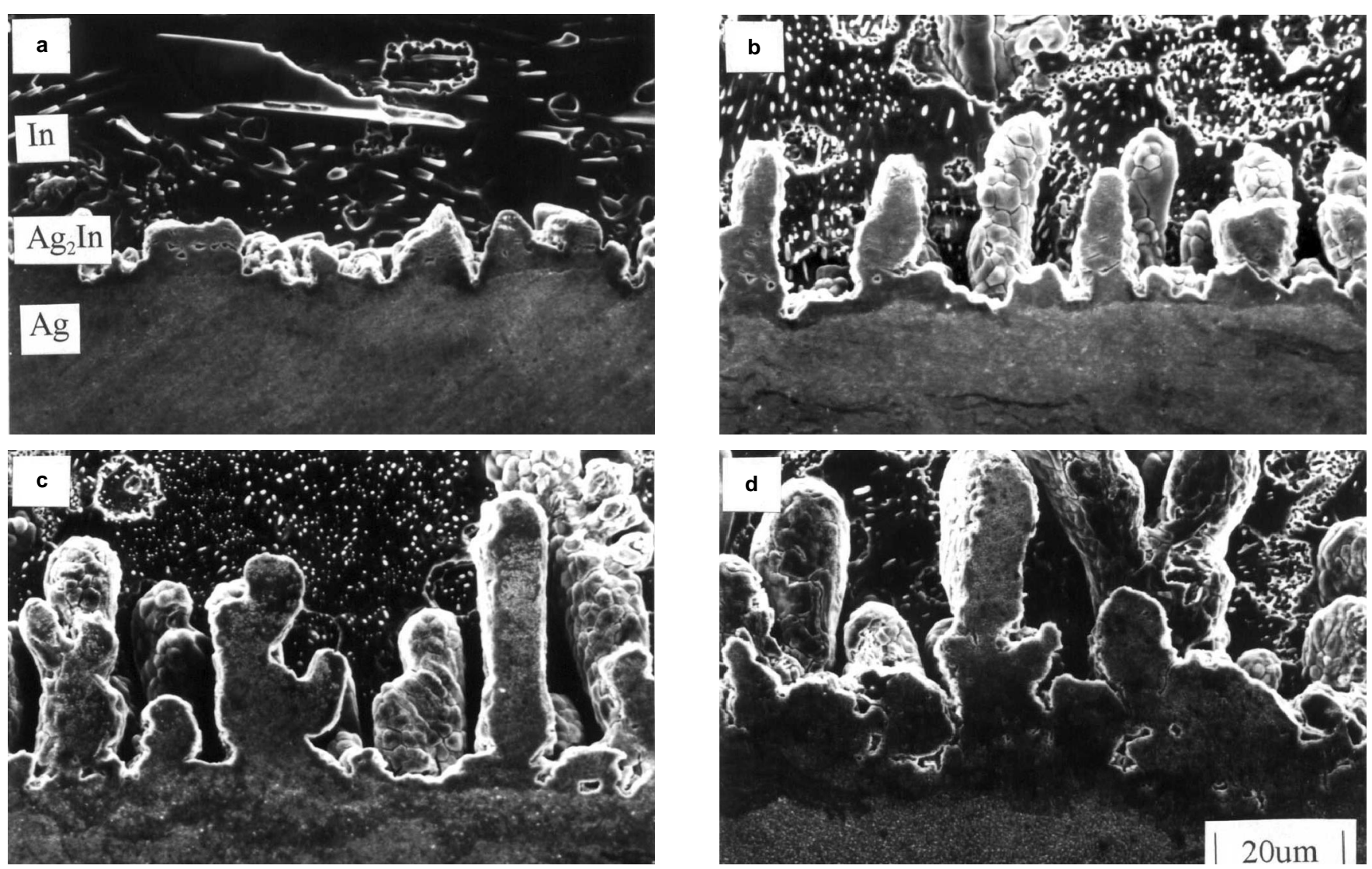

Fig. 2. Morphology of Ag/ln interfacial reaction product (a) $498 \mathrm{~K}, 30 \mathrm{~min}$; (b) $548 \mathrm{~K}, 30 \mathrm{~min}$; (c) $598 \mathrm{~K}, 30 \mathrm{~min}$; and (d) $648 \mathrm{~K}, 30 \mathrm{~min}$. 


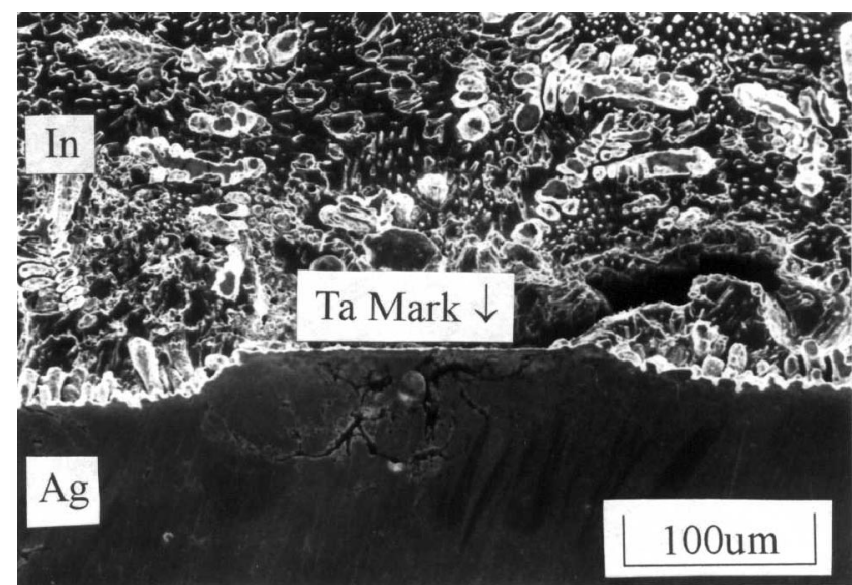

Fig. 3. Result of Ta-marked experiment showing migration of $\mathrm{Ag}_{(\mathrm{s})} /$ $\mathrm{In}_{(1)}$ interface towards the $\mathrm{Ag}$ substrate. Sample reaction time: $20 \mathrm{~min}$ at $573 \mathrm{~K}$.

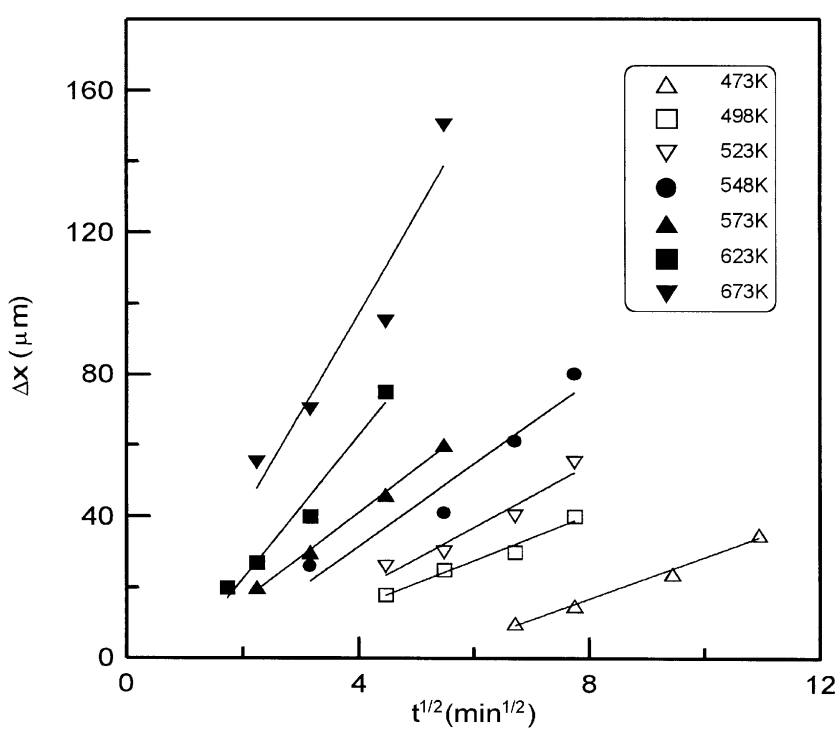

Fig. 4. The thickness of $\mathrm{Ag}_{2} \mathrm{In}$ intermetallic compound against the square root of reaction time, for samples reacted in the temperature range from $473 \mathrm{~K}$ to $673 \mathrm{~K}$.

polished with $1 \mu \mathrm{m}$ and $0.3 \mu \mathrm{m}$ alumina powder. The intermetallic compounds and their interfaces with indium were selectively etched using a solution of $10 \mathrm{ml} \mathrm{HF}, 10 \mathrm{ml} \mathrm{H}_{2} \mathrm{O}_{2}$, and $40 \mathrm{ml} \mathrm{H}_{2} \mathrm{O}$. Most of the observations were conducted using a scanning electron microscope (SEM). The intermetallic compounds were identified with electron microprobe analysis (EPMA) and x-ray diffraction (XRD). For further clarification of the formation mechanism of intermetallic compounds during the soldering reaction, the original $\mathrm{Ag}_{(\mathrm{s}} / \mathrm{In}_{(\mathrm{l})}$ interface was marked by sputteringdeposition of a Ta thin film on a partial region of $\mathrm{Ag}$ substrates. Ta does not react with $\mathrm{Ag}$ and In, and the deposition of the Ta thin film acted as a diffusion barrier at the $\mathrm{Ag}_{(\mathrm{s})} / \mathrm{In}_{(\mathrm{l})}$ interface identifying the original $\mathrm{Ag}_{(\mathrm{s})} / \mathrm{In}_{(\mathrm{l})}$ interface.

Wettability was evaluated by placing an indium cylinder with $2 \mathrm{~mm}$ diameter and $2 \mathrm{~mm}$ height on a silver substrate in an infrared furnace under a vacuum of $10^{-3}$ torr. Before the test, the indium cylinders were
Table I. Parabolic Growth Constants $\left(k_{p}\right)$ of Intermetallic Layers Formed during the In/Ag Interfacial Reactions

\begin{tabular}{lc}
\hline $\begin{array}{l}\text { Reaction } \\
\text { Temperatures } \\
(\mathbf{K})\end{array}$ & $\begin{array}{c}\text { Parabolic Growth } \\
\text { Constants }\left(\mathbf{k}_{\mathbf{p}}\right) \\
\left(\mathbf{c m}^{2} / \mathbf{s e c}\right)\end{array}$ \\
\hline 473 & $6.07 \times 10^{-5}$ \\
498 & $7.59 \times 10^{-5}$ \\
523 & $9.11 \times 10^{-5}$ \\
548 & $1.44 \times 10^{-4}$ \\
573 & $1.59 \times 10^{-4}$ \\
623 & $2.12 \times 10^{-4}$ \\
673 & $2.88 \times 10^{-4}$ \\
\hline
\end{tabular}

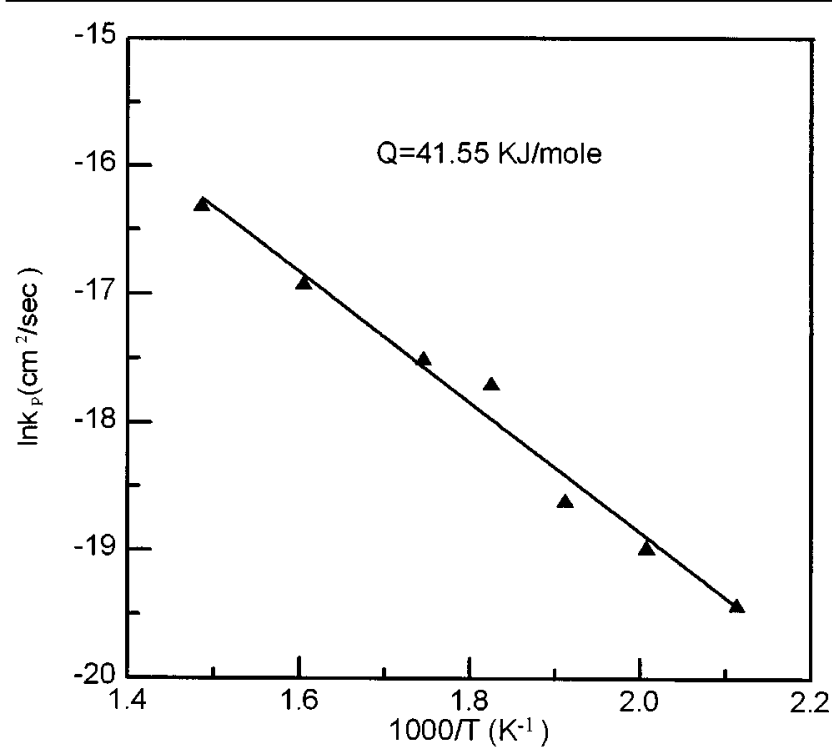

Fig. 5. Arrhenius plot of the growth rate constant versus reaction temperatures during $\mathrm{Ag} / \mathrm{In}$ interfacial reaction.

dipped in a mildly activated rosin flux. During heating, the contact angles of the sessile drops were measured continuously by video camera.

\section{RESULTS AND DISCUSSION}

Figures 1 and 2 show the morphology of intermetallic compounds formed at the In/Ag interfaces. The micrographs indicate that the intermetallic compounds have a scallop morphology and grow from the In/Ag interface into the silver substrates. The $\mathrm{Ag}_{(\mathrm{s})} / \mathrm{In}_{(\mathrm{l})}$ interface migrated toward the Ag substrate (Fig. 3). The formation of the scallop-shaped intermetallic compounds resulted from the dissolution of Ag into the In solder. EPMA and XRD analyses revealed that the scallops are $\mathrm{Ag}_{2} \mathrm{In}$. As reaction time (Fig. 1) and reaction temperature increased (Fig. 2), the $\mathrm{Ag}_{2}$ In intermetallic compounds grew in width but decreased in number. This suggests that a ripening reaction accompanies the growth of the intermetallic compounds.

The morphology of the reaction fronts was somewhat irregular so the growth thickness was calculated through dividing the total area of intermetallics spread out on the micrograph by the width of these 


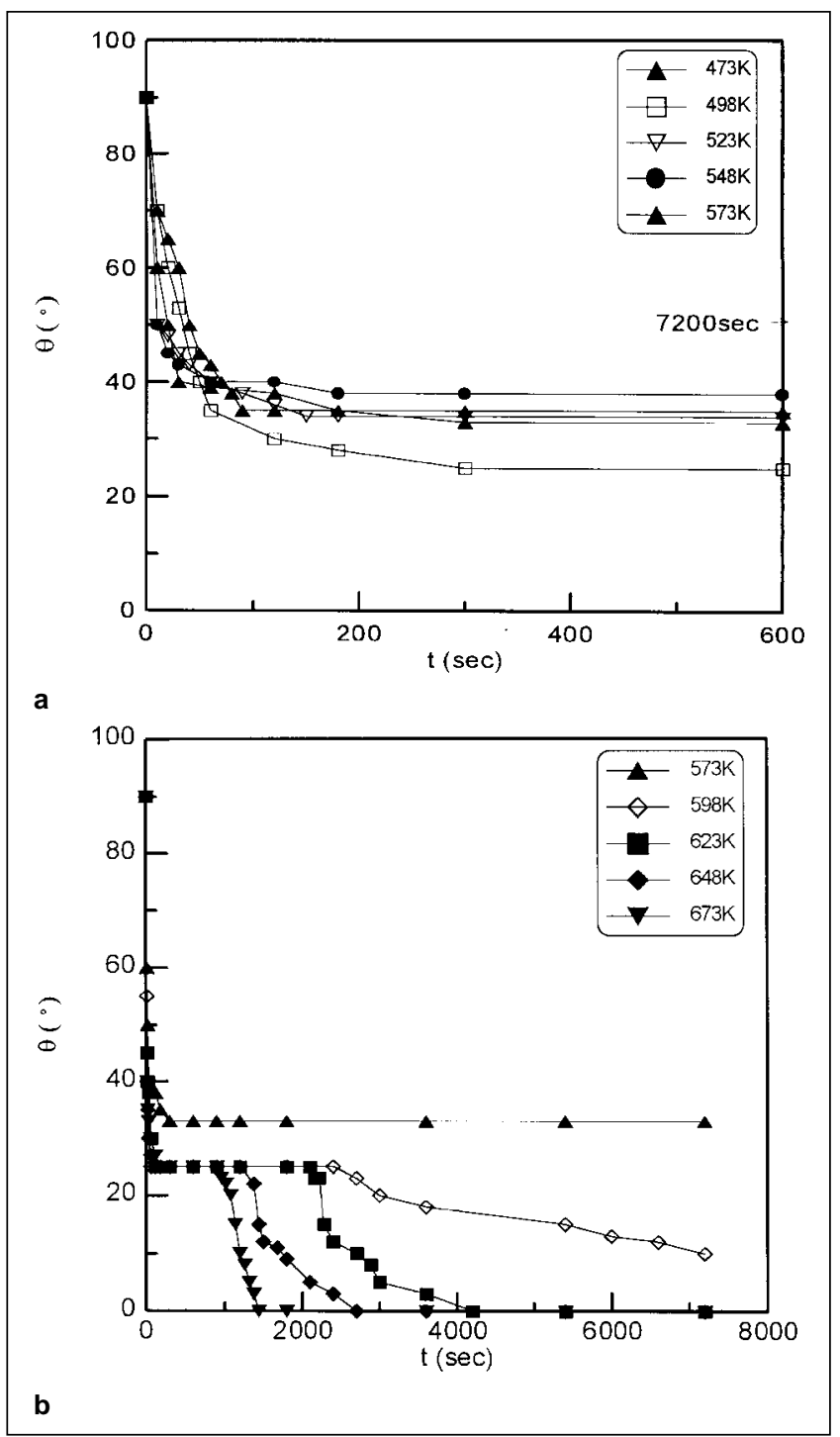

Fig. 6. (a) Plot of contact angles versus reaction time at temperatures ranging from $473 \mathrm{~K}$ to $573 \mathrm{~K}$; (b) plot of contact angles versus reaction time at temperatures ranging from $573 \mathrm{~K}$ to $673 \mathrm{~K}$.

intermetallics. The growth thickness $(\Delta \mathrm{x})$ in relation to square root of the reaction time $(\mathrm{t})$ was plotted in Fig. 4. The standard deviation for intermetallic layers was between $0.2 \mu \mathrm{m}$ and $1.5 \mu \mathrm{m}$. In Fig. 4 , the growth rate of $\mathrm{Ag}_{2}$ In had a t/1/2 dependence. This indicates that parabolic growth was observed in the case of these interfacial reactions, and the growth of intermetallic compounds was diffusion-controlled.

The parabolic growth constants $\mathrm{k}_{\mathrm{p}}$,

$$
\mathrm{k}_{\mathrm{p}}=\Delta \mathrm{x}^{2} / \mathrm{t}
$$

for various reaction temperatures are given in Table $\mathrm{I}$. Figure 5 shows an Arrhenius plot of these parabolic growth constants. The activation energy determined from this plot was $41.55 \mathrm{KJ} / \mathrm{mol}$, similar to that of $53.6 \mathrm{KJ} / \mathrm{mol}$ for lattice diffusion of Ag in In as reported by Anthony and Turnbull. ${ }^{10}$ This indicates that the growth mechanism of intermetallic compounds during interfacial reactions was diffusion of silver through the molten indium between the intermetallic scal-

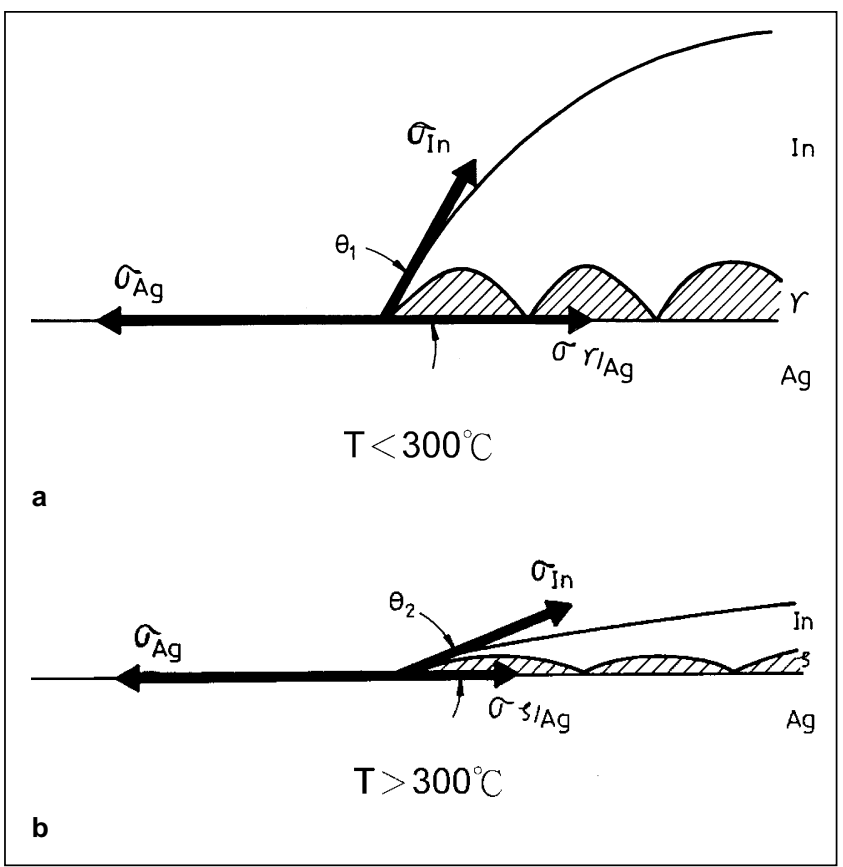

Fig. 7. Schematic diagram of the related interfacial energies at the tip of indium sessile drop at the temperatures (a) below and (b) above $573 \mathrm{~K}$.

lops, also resulted in the ripening of the scallop-type intermetallic compounds. The growth mechanism was similar to that of $\mathrm{Cu}_{6} \mathrm{Sn}_{5}$ formed between the eutectic $\mathrm{SnPb}$ solder and $\mathrm{Cu} .{ }^{11,12}$

The contact angles, measured from the sessile drops of liquid indium on the surface of silver substrates at various temperatures, were plotted as a function of time as shown in Fig. 6. Figure 6a shows that, at temperatures below $573 \mathrm{~K}$, the contact angles decreased with time and remained at a constant value between $25^{\circ}$ and $40^{\circ}$. At temperatures above $573 \mathrm{~K}$, the contact angles also decrease to a value of about $25^{\circ}$. However, after remaining constant for a brief period of more than $15 \mathrm{~min}$, the contact angles further decreased to a much lower value near zero, as shown in Fig. 6b. The intervals of such a transient plateau with constant contact angles decreased corresponding with the increase of temperatures from $598 \mathrm{~K}$ to $673 \mathrm{~K}$. From the $\mathrm{Ag}$-In phase diagram, ${ }^{13}$ the $\mathrm{Ag}_{2} \mathrm{In}$ intermetallic compound appeared as $\gamma$ (below $573 \mathrm{~K}$ ) and $\zeta($ above $573 \mathrm{~K})$ phases. The different wetting behavior of liquid indium on silver below, and above, $573 \mathrm{~K}$ is explained schematically in Fig. 7. In Fig. 7, the interfacial reaction products between liquid indium and silver substrate were $\gamma-\mathrm{Ag}_{2}$ In and $\zeta-\mathrm{Ag}_{2} \mathrm{In}$ for the temperatures below and above $573 \mathrm{~K}$, respectively. The equilibrium equations of the related interfacial energies at the tip of the indium sessile drop could be expressed as:

$$
\begin{gathered}
\sigma_{\mathrm{Ag}}=\sigma_{\mathrm{n}} \cos \theta_{1}+\sigma_{\gamma / \mathrm{Ag}}(\mathrm{T}<573 \mathrm{~K}) \\
\sigma_{\mathrm{Ag}}=\sigma_{\mathrm{In}} \cos \theta_{2}+\sigma_{\zeta / \mathrm{Ag}}(\mathrm{T}>573 \mathrm{~K})
\end{gathered}
$$

where $\sigma$ is the interfacial energy, and $\theta_{1}$ and $\theta_{2}$ represent the contact angle.

Since the $\gamma-\mathrm{Ag}_{2}$ In phase possesses an isotypic crys- 
tal structure with $\gamma$-brass (lattice parameter a $=$ $9.905 \mathrm{~A})^{14}$ and the $\zeta-\mathrm{Ag}_{2} \mathrm{In}$ phase is hcp-structure (lattice parameters: $\mathrm{a}=2.95 \AA, \mathrm{c}=4.80 \AA$ ) ${ }^{15}$ the lattice mismatch of the $\gamma / \mathrm{Ag}$ interface is much larger than the $\zeta / \mathrm{Ag}$ interface, as Ag has an fcc-structure with a lattice parameter of $\mathrm{a}=4.09 \AA$. Therefore, the interfacial energy of $\gamma / \mathrm{Ag}$ was much greater than that of $\zeta / \mathrm{Ag}$, resulting in $\theta_{1}>>\theta_{2}$. The complete wetting of indium on silver substrates above $573 \mathrm{~K}$ was therefore reasonable in comparison with the wetting below $573 \mathrm{~K}$.

\section{CONCLUSIONS}

During the interfacial reactions of liquid indium with silver substrates in the temperature range between $473 \mathrm{~K}$ and $673 \mathrm{~K}$, the intermetallic compound $\mathrm{Ag}_{2}$ In forms in the morphology of scallops. With an increase in reaction temperature, the $\mathrm{Ag}_{2}$ In intermetallic scallops grew in size and decreased in number. The growth of the intermetallic compound is parabolic as a function of time indicating that the reaction was diffusion-controlled. The activation energy calculated from the Arrhenius plot of growth reaction constants was $41.55 \mathrm{KJ} / \mathrm{mole}$, consistent with that for the lattice diffusion of $\mathrm{Ag}$ in In (53.6 KJ/mole). This indicates that the growth mechanism of intermetallic compounds during interfacial reaction was the diffusion of silver in molten indium.

The wetting behavior of liquid indium on the surface of silver substrates at temperatures below, and above, $573 \mathrm{~K}$ were quite different. Below $573 \mathrm{~K}$, the contact angles decreased drastically with time and remained at constant values between $25^{\circ}$ and $40^{\circ}$.
Above $573 \mathrm{~K}$, the contact angles declined rapidly initially to a value of approximately $25^{\circ}$, then remained constant for a short period of time, and eventually decreased again to a value near zero. Such different wetting behaviors could be explained by the different crystal structures $\left(\gamma\right.$ and $\zeta$ ) of the $\mathrm{Ag}_{2} \mathrm{In}$ intermetallic compound that forms at temperatures below, and above, $573 \mathrm{~K}$. The lattice mismatch of the $\gamma / \mathrm{Ag}$ interface was much larger than that of the $\zeta / \mathrm{Ag}$ interface that results in a much greater interfacial energy, and poorer wetting of the $\gamma / \mathrm{Ag}$ interface.

\section{REFERENCES}

1. J. Glazer, J. Electron. Mater. 23, 693 (1994).

2. S.K. Kang and A.K. Sarkhel, J. Electron. Mater. 23, 701 (1994).

3. W.J. Plumeridge, J. Mater. Sci. 31, 2501 (1996).

4. J. Campbell and H. Conrad, J. Electron. Pkg., Trans. ASME 117, 241 (1995).

5. C.R. Hall, and EI.B. Hannech, Mater. Sci. and Tech. 8, 930 (1992).

6. X.H. Wang and H. Conrad, Scripta Metall. Mater. 30, 725 (1994).

7. L. Bernstein, J. Electrochem. Soc. 113, 1282 (1966).

8. L. Bernstein and H. Bartholomew, Trans. Metall. Soc. AIME 236, 405 (1966).

9. D.M. Jacobson and G. Humpston, Soldering and Surf. Mount Technol. 10, 27 (1992).

10. T.R. Anthony and D. Turnbull, Phys. Rev. 151, 495 (1966).

11. K.N. Tu, Acta Metall. 21, 347 (1973).

12. K.N. Tu, Mater. Chem. Phys. 46, 217 (1996).

13. T.B. Massalski, editor, Binary Alloy Phase Diagrams (Materials Park, OH: American Society for Metals, 1986), p. 32.

14. V.M. Goldschmidt, Z. Physik. Chem. 133, 397 (1928).

15. W. Hume-Rothery, J.O. Betterfon, and J. Reynolds, J. Inst. Metals 80, 609 (1951). 